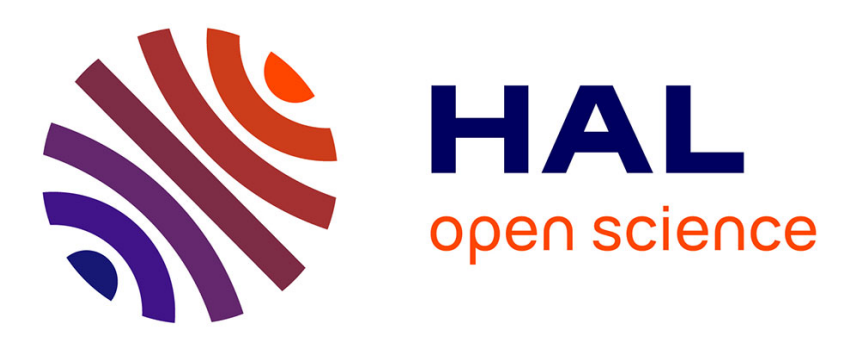

\title{
Biofilm productivity and concomitant cell autolysis in a membrane bioreactor
}

\author{
S. Govender
}

\section{To cite this version:}

S. Govender. Biofilm productivity and concomitant cell autolysis in a membrane bioreactor. Biotechnology Letters, 2010, 33 (2), pp.263-271. 10.1007/s10529-010-0443-1 . hal-00634805

\section{HAL Id: hal-00634805 \\ https://hal.science/hal-00634805}

Submitted on 24 Oct 2011

HAL is a multi-disciplinary open access archive for the deposit and dissemination of scientific research documents, whether they are published or not. The documents may come from teaching and research institutions in France or abroad, or from public or private research centers.
L'archive ouverte pluridisciplinaire HAL, est destinée au dépôt et à la diffusion de documents scientifiques de niveau recherche, publiés ou non, émanant des établissements d'enseignement et de recherche français ou étrangers, des laboratoires publics ou privés. 
Section: Bioprocessing and Bioengineering

Biofilm productivity and concomitant cell autolysis in a membrane bioreactor

S. Govender ${ }^{\text {a,b }}$

anstitut für Biochemie, Technische Universität Dresden, D-01062, Dresden, Germany,

${ }^{\mathrm{b}}$ Council for Scientific \& Industrial Research, CSIR Built Environment, PO Box 395, 0001, Pretoria, RSA

- To whom all correspondence should be addressed

Dr. Selvan Govender

CSIR Built Environment, Council for Scientific \& Industrial Research, PO Box 395, 0001, Pretoria, RSA

Email: selvan.govender@daad-alumni.de

Tel: $\quad+27128412497$

Fax: $\quad+27128414064$ 


\begin{abstract}
Phanerochaete chrysoporium morphology and manganese peroxidase (MnP) productivity was characterised in a scalable, modularised $1145 \mathrm{~cm}^{3}$ membrane gradostat reactor in response to switching between an enhanced production medium and a nutrient limited feed (50\% $\mathrm{C}$ and $\mathrm{N}$ reduction). Irrespective of the feed composition used nutrients permeating from the lumen of the ultrafiltration membrane matrix established nutrient gradients across the immobilised biofilm with distinct primary, stationary and decline growth phases observed. Severe nutrient $\mathrm{C}$ and $\mathrm{N}$ limitation did not change the cyclic nature of enzyme production $\left(\mathrm{MnP}_{\max }=189.5 \mathrm{U} \mathrm{l}^{-1}\right)$ but did reduce the overall bioreactor efficiency from $32 \mathrm{U} \mathrm{l}^{-1} \mathrm{~d}^{-1}$ to $22 \mathrm{U} \mathrm{l}^{-1} \mathrm{~d}^{-1}$. Stress induced secondary metabolism resulted in concomitant cell autolysis causing biomass loss and increased operational flux after 20 days in the 33 day bioreactor operation cycle.
\end{abstract}

\title{
Key Words
}

Gradostat, manganese peroxidase, membrane bioreactor, nutrient manipulation, Phanerochaete chrysoporium, white rot fungi 
Introduction

Fungi produce a wide range of secondary metabolites which are of medical, agricultural and industrial relevance. Most fungi display filamentous growth. Their biosynthetic genes are clustered and conserved between organisms. This, together with the attendant physiological costs, suggests that these complex compounds could only be produced to benefit the organism even though many reports do not show any link to their survival (Calvo et al. 2002). White rot fungi (WRF), such as the aerobic, shear sensitive basidiomycete Phanerochaete chrysosporium produce extracellular enzymes for lignin degradation based on an environmentally-induced physiological response to severe nutrient limitation (Mikiashvilli et al. 2005). These industrially and environmentally important ligninase enzymes (manganese peroxidases, lignin peroxidases and laccases) also degrade persistent xenobiotic chemicals. This has initiated significant research effort towards large scale enzyme production and recovery and or bioremediation. (Cabuk et al. 2006).

Commercial production of useful primary and secondary metabolites is often achieved by controlling the expression of genes involved in secondary metabolite production via manipulation of the growth nutrients or the specific environmental conditions. Nutrient limitation results in a lower growth rate and, in the case of WRF, this is a precursor to ligninase production where, in nature, it would be followed by further growth cycles once delignification makes more nutrients available. Based on the requirements for WRF, bioreactor design and consideration of the native state of the fungus, the gradostat bioreactor concept evolved as a viable option for continuous production of idiophasic enzymes and for bioremediation (Leukes et al. 1996; Ntwampe et al. 2008). The term gradostat applies because bi-directional contact occurs between the primary and secondary growth phases of the biomass, albeit that gas and liquid flow is uni-directional. The immobilised fungus mimicked the native growth and development of the basidiomycete in response to applied environmental stress, while the polymeric membrane provided a support matrix for physical retention of spores, space for subsequent germination and mechanical strength to accommodate the developing mycelium. Previous studies have followed the continuous fed bioreactor protocol of continuously supplying cells with substrate at growth limiting concentrations which maintain the cells in the exponential phase. 
The membrane gradostat reactor (MGR) concept focuses on $\mathrm{C}, \mathrm{N}$ and $\mathrm{S}$ limitation for high levels of $\mathrm{MnP}$ and lignin peroxidase (LiP) production, but the physiological and morhological effects are yet to be described and understood. An inherent feature of enzyme production in a gradostat reactor is the cyclic nature of extracellular MnP production. MGRs rely on biofilm development and the formation of nutrient gradients for idiophasic enzyme production. However excessive biofilm development which often sloughs off the membrane and blocks the reactor ports, coupled with cyclic enzyme production have hampered reactor efficiency and subsequently generated interest in nutrient manipulation and controlling the biofilm growth rate and morphology to improve enzyme productivity. Besides mimicking the native state of the WRF and complementing the biotransformation process, the MGR, coupled with a 'quality by design' approach to scale-up, also offers more operational freedom in addressing traditional bioreactor scale-up challenges such as maintaining homogeneity and adapting to gradients at a large scale. As such, the MGR has evolved via various bioreactor configurations from transverse-flow modules (Leukes, 1996) to capillary axial flow-modules (Govender et al. 2004; Ntwampe et al 2008).

This study investigates the nutrient supply regime ( $\mathrm{C}$ and $\mathrm{N}$ ratios) compared with a recently developed production medium (Govender et al. 2010) and characterises the morphological and physiological response of immobilised $P$. chrysosporium, subjected to nutrient limitation in an axial-flow, $1145 \mathrm{~cm}^{3}$ multi-capillary MGR. Manipulation of C, N, S and trace element nutrients for over production of MnP were investigated in relation to the spatial and temporal distribution of mycelial biomass within the membrane matrix. Oxygenation was provided in excess using both sterile air and $100 \% \mathrm{O}_{2}$, while shear stress was kept to a minimum. The impacts on fungal growth and enzyme production are described using enzyme assays and ultrastructural analysis. 


\section{Materials and Methods}

Microorganism, media and inoculum preparation

Phanerochaete chrysosporium ME446, maintained on 2\% (w/v) malt extract/agar plates, was incubated at $39^{\circ} \mathrm{C}$ for $10 \mathrm{~d}$, prior to spore harvesting while the resulting conidial spores were prepared by suspending the spores in sterile, deionised water followed by filtration through sterile glass wool to free it of mycelia. Spore concentration was determined by $\mathrm{OD}_{650}$. A production medium, supplemented with phospholipids and surfactants and characterised in a recent study (Govender et al. 2010) was used as a control in this study.

Membrane Preparation

Externally unskinned, anisotrophic polysulfone (PSU) capillary membranes were manufactured using the wet phase inversion process and the unique substructure morphology was designed to have low resistance to liquid transport and a large external surface area (Leukes et al. 1996). The well-defined ultrafiltration (UF) internal skin layers consisting entirely of closely packed and narrow-bore microvoids that extended from just below the internal skin layer of the membrane to the periphery, providing physical support for the growing fungal biofilm.

Gradostat bioreactor operation

Spores were immobilised in the membrane microvoid cavities by reverse filtration and was optimised (Govender et al. 2004) to improve consistency in biofilm development. Membrane gradostat reactors (MGR), using externally unskinned UF capillary membranes as immobilisation matrices, were operated under the conditions described in Table 1. The MGR was dependent on aeration to generate a biofilm and to stimulate ligninase production. The air-flow regime consisted of pumping in sterile air via a 
peristaltic pump and supplementing with intermittent flushing of the reactor with $100 \% \mathrm{O}_{2}$ for 10 min every $12 \mathrm{~h}$. The complete process flow diagram for continuous operation is illustrated in Fig. 2. The operational conditions selected for continuous operation were based on previous work with this gradostat system (Ntwampe et al. 2008; Govender et al. 2003) and were kept constant for the duration of continuous operation with changes made dependent on the nutrient switching scheme. MGR efficiency in this study was based on the average MnP production per day of operation.

Nutrient gradient manipulation

According to the Monod model, in the steady state the specific growth rate will equal the dilution rate. Thus the specific growth rate may be controlled by altering the dilution rate or adjusting the rate of supply of fresh feed. This is normally used to investigate growth at submaximal rates (Gow and Gadd, 1995). The advantage of controlling the specific growth rate in a MGR is that extended operation in the stationary phase could become possible. However, this is extremely difficult to achieve with the multicapillary MGR since it is a novel design and prior knowledge of optimal dilution rates would be required from the outset. The only 'known' criterion pertinent to biofilm growth available at the outset is the limiting substrate $(\mathrm{C}$ and $\mathrm{N})$ concentration in the growth medium. Once MnP production was detected, it was assumed that a significant portion of the biofilm was in the stationary phase. It is hypothesised that by reducing the influx concentration of nutrient $\mathrm{C}$ and $\mathrm{N}$ it would be possible to maintain steady state production of $\mathrm{MnP}$ by controlling the growth phase (i.e. the stationary phase) of the immobilised biomass. The said nutrient stress was created by reducing the feed concentration of glucose $[10 \%(\mathrm{w} / \mathrm{v})$ to $5 \%(\mathrm{w} / \mathrm{v})]$ and total nitrogen $[1 \%(\mathrm{w} / \mathrm{v})$ to $0.5 \%(\mathrm{w} / \mathrm{v})]$ by an empirical value of $50 \%$ whilst leaving the dilution rate constant. 
Enzyme activity and productivity

Mn (II) dependent peroxidase activity was determined by monitoring the oxidation of guiaicol spectroscopically. One unit of activity is defined as the initial increase in absorbance at $465 \mathrm{~nm}$ of 1 per min, and activities are reported in $\mathrm{U}^{-1}$ while productivity was defined as the amount of product formed per unit reactor volume (Govender et al. 2004). A glucose oxidase assay kit (Sigma) was used to determine residual glucose concentration, typically analysed for in the permeate flask. Residual nitrogen was measured at 400nm using Nessler's Reagent (Sigma). Unless otherwise stated all chemicals were purchased from Sigma, RSA.

Electron microscopy

For scanning electron microscopy (SEM), PSU membrane sections were fixed for $2 \mathrm{~h}$ in $5 \%(\mathrm{v} / \mathrm{v})$ glutaraldehyde with $0.1 \mathrm{M}$ phosphate buffer at $4^{\circ} \mathrm{C}$ and $\mathrm{pH} 7.5$, after which the sections were dried in a water:ethanol gradient. Cross-sections of the membranes were prepared by freeze fracturing with liquid $\mathrm{N}_{2}$ and examined using a Hitachi S-570 SEM (Japan). Fungal tissue to be analysed by transmission electron microscopy (TEM) were fixed in fresh glutaraldehyde, washed in two changes of $0.05 \mathrm{M}$ cacodylate buffer and post-fixed using $\mathrm{OsO}_{4}$. After at least two washes of $30 \mathrm{~min}$ each, the material was dehydrated in a graded alcohol series and then embedded in Spurrs resin, followed by sectioning, post fixation with uranyl acetate and $\mathrm{Pb}$ citrate and viewed with a JEOL 1210 TEM. 


\section{Results and discussion}

Biomass morphology and productivity

Contrary to the practice of using separate germination and production media (Venkatadri and Irvine, 1993), this study used an enhanced production medium (Govender et al. 2010). The pump flow rate was kept constant so as to minimise the influence of hydrodynamic parameters on enzyme production and biofilm development. Different growth phases, i.e. primary, stationary and decline phases, were observed radially across the biofilm (Fig 3) after sectioning along the length of the capillary membrane. This observation was consistent with both the control and the nutrient limited feed and visual assessment of the membrane surface showed an initial dense, white biofilm which turned yellow/brown at the onset of ligninase enzyme production (Fig. 4). The colour change was attributed to the presence of excess trace elements in the feed solution. These observations were also characterised by both colour changes in the mycelium (Fig. 4b) and SEM observations of the fungal morphology indicating significant biofilm development which was further supported by trends in the permeation rate decrease in Fig. 4a, limiting the flux through the membrane.

Studies have shown that the morphology of the fungal mycelia can be related to their physiological state (Rittman et al. 1992). This morphological diversity; if regulated by controlling the operational regime could be an important parameter for optimal production of enzymes or other secondary metabolites in an MGR by selecting for a morphological growth phase that compliments the physiological secondary metabolite phase as correlated by other reports (Leukes et al. 1996; Rittman et al. 1992). From Fig 3, morphological differentiation occurs laterally as a function of the state of growth, which, in turn, is a function of the nutrient supply in response to spatial gradients radially across the biofilm.

SEM analysis shows different growth phases [primary (extension and production zone A), stationary (sporulation zone B) and decline (ageing zone C)] along the cross-sectional length of a single capillary 
membrane. The primary growth phase (zone A) was characterised by germinating spores and surface colonization with exploratory hyphae. Zone B consisted mostly of highly branched and fragmented hyphae, typical of the stationary phase. A high level of fragmentation is thought to occur due to increased vacuolation rather than just mechanical shear stress. Zone $\mathrm{C}$ (decline phase) shows a combination of copious conidiating mycelium and sloughing off of dead biomass followed by biofilm proliferation in the nutrient rich regions of the biofilm with the older biomass being pushed outwards towards the $\mathrm{O}_{2}$ richer zone and finally necrotic spaces that were later observed indicating a loss of biofilm and concomitant hyphal autolysis

Nutrient gradient manipulation

The concentrations of glucose and total $\mathrm{N}$ in the feed system were reduced by $50 \%(\mathrm{w} / \mathrm{v})$ after 9 days as this was typically when one cycle of continuous production of MnP stopped and a few days before the onset of a new cycle. The subsequent cyclic MnP production could last considerably longer, due to the temporal and spatial domains generated radially within the immobilised fungal biomass by manipulating the concentration of glucose and or nitrogen in the inflowing medium which would then limit exponential growth as a consequence of continuous availability of the fresh medium. The advantage of controlling the specific growth rate in a MGR is that extended operation in the stationary phase for the idiophasic production of ligninases would become possible. However, this is extremely difficult to achieve with the multi-capillary MGR due to the as yet un-characterised design while a prior knowledge of optimal dilution rates would be required from the outset. The permeate aminonitrogen concentration decreased sharply during the initial germination and growth phase, but this rate of decline became less pronounced when culture age increased (Fig 5b). Glucose concentrations (Fig 5a) also declined rapidly as biofilm growth proliferated in zone A. This coincided with a rapid decrease in the permeation rate (Fig 4a). When fresh medium was introduced, growth proceeded as the feed permeated the immobilised biofilm, until the concentration of one particular nutrient component was reduced to a level at which it limited the specific growth rate (Gow and Gadd, 1995). Increases in biomass lead to a decrease in substrate concentration and specific growth rate until balance is reached between biomass production and removal of nutrient through washout. 
The reduction of the nutrient levels, however, resulted in another series of cyclic MnP production with peak MnP production of $190 \mathrm{U} \mathrm{l}^{-1} \mathrm{~d}^{-1}$ after 9 days compared to $250 \mathrm{U} \mathrm{l}^{-1} \mathrm{~d}^{-1}$ with the control feed (PM) after 7 days of continuous operation (Fig. 5c). This was exacerbated by the observation of 'bare' patches or necrotic zones on the biofilm. Here the level of mycelial 'removal' via hyphal autolysis and sloughing off was so intense that the native surface of the capillary membrane could be seen. MnP production was almost undetectable after 21 days and the increase in the permeation rate indicated a loss of immobilised biofilm (Fig. 4). The greater efficiency shown using the control or production medium (32 $\mathrm{U} \mathrm{l}^{-1} \mathrm{~d}^{-1}$ compared to $22.5 \mathrm{U} \mathrm{l}^{-1} \mathrm{~d}^{-1}$ ) suggested that a thick biofilm and high flux range increased efficiency, most likely due to an adequate supply of nutrients and a residence time within the adsorptive capacity of the MGR. Addition of fresh nutrients (during the feed switch to nutrient limitation) led to a comparable second cycle of $\mathrm{MnP}$ production (Fig. 5c) in spite of the concomitant cell ageing (Fig. 6) which could also be due to the removal of additional metabolic wastes expected to back-diffuse into the lumen via re-circulation. The peak MnP production of $250 \mathrm{U} \mathrm{l}^{-1} \mathrm{~d}^{-1}$ with the 1145 $\mathrm{cm}^{3}$ multi-capillary MGR is also a $45 \mathrm{x}$ volumetric and a $12 \mathrm{x}$ geometric scale-up of a $25 \mathrm{~cm}^{3}$ single capillary MGR described by Govender et al. (2010) resulting in an $8.3 \mathrm{x}$ increase in MnP productivity in contrast to a $6 \mathrm{x}$ increase with the nutrient-manipulated, substrate-limiting feed system. This suggests that scale effects in the MGR were not as significant as manipulation of the nutrient gradient.

Fungal physiological response

TEM analysis of sloughed off biofilm in the permeate line showed cell autolysis after 16 days of operation (Fig. 6a) while biofilm scraped of the capillary at the end of the 33 day cycle contained hyphae that had undergone severe autolysis. Glycogen deposits (another sign of cell aging) was also observed (Fig. 6). Hyphal autolysis was directly linked to loss of secondary metabolite production potential of Penicillium chrysogenum (Pusztahelyi et al. 1997). This could account for the absence of MnP activity during the latter stages of the run (days 25 -33) when hyphal autolysis was most severe. Despite the restoration of the initial nutrient concentrations after 16 days hyphal degradation persisted until the end of the 33 day study period. An interesting observation was the formation of dolipore septa (Fig. 6b). Dolipore septa are elaborate septal complexes found in most fungi but their role in fungal physiology is still not very clear (Gow and Gadd, 1995). Doplipore septa form in situations of extreme 
cell trauma or stress or even during ageing (Alymore et al. 1984). The presence of paranthesomes (Fig 6b) supports this phenomenon because they are generally considered to provide a protective or selective function by regulating the cytoplasm immediately adjacent to the septal swellings and pores (Alymore et al. 1984; Gow and Gadd, 1995). Under the severe nutrient limitation conditions imposed by extended operation of the membrane gradostat reactor, it seemed plausible that the formation of dolipore septa played a role in structural support, hyphal tip growth and maintaining rigidity of the hyphae.

Fig 6c depicts a SEM profile of a region of the capillary membrane where the biofilm was undergoing cell autolysis and formation of septa. The thick layer on the sloughed off biofilm surface was confirmed using IR spectroscopy as an extracellular polysaccharide sheath that built up around aging hyphae. Acid hydrolysis of these polysaccharides revealed predominantly glucose units linked by $\beta$ bonds evident from the $890 \mathrm{~cm}^{-1}$ band in the IR spectra. Typically in nature, ligninolytic fungi use sheath polysaccharides to degrade lignin in wood by facilitating the joint action of enzymes providing a source of reducing power, and assisting in the diffusion of redox intermediates (Gutiérrez et al. 1995).

\section{Conclusions}

Switching from an enhanced production medium to an extremely $\mathrm{C}$ and $\mathrm{N}$ deficient feed early in the MGR operation cycle, did not change the general growth profile of the immobilised biofilm, with all three growth phases clearly documented. However, the nutrient limitation studies did not lead to an increase in MnP productivity (30\% loss of bioreactor efficiency) or a deviation from cyclic $\mathrm{MnP}$ production. Moreover, the impact of nutrient starvation was extremely profound on the biofilm resulting in severe hyphal autolysis and visible loss of biofilm with predominance of the decline phase of growth. The formation of dolipore septa, the extensive polysaccharide build up on the capillary membranes and degenerating hyphae indicate the extent of stress and ageing of mycelia as a result of severe nutrient limitation. These results are useful for future work involving monitoring of glucose influx regime and the morphological growth state described could serve as an ultrastructural 'marker' for cells undergoing severe nutrient limitation and autolysis. Furthermore, this study shows that scale effects due to the transition from a $25 \mathrm{~cm}^{3}$ to $1145 \mathrm{~cm}^{3}$ MGR were not as significant as manipulation of 
the nutrient feed regime, which has a concomitant effect on biofilm morphology and physiology. A better understanding of the interplay between the growth limiting substrates and biofilm dynamics, coupled with knowledge of an optimal dilution rate could improve efficiency and induce the stationary phase to predominate across the biofilm for long term steady state enzyme production using the MGR.

\section{Ackowledgements}

This study was supported by the National Research Foundation and the Deutscher Akademischer Austausch Dienst.

\section{References}

Alymore RC, Wakley GE, Todd NK (1984) Septal sealing in the basidiomycete Coriolus versicolor. J Gen Microbiol 130: 2975 - 2982

Aster M, Lesage L, Drapron, R, Corrieu, G. and E. Odier (1988) Phospholipid and fatty acid enrichment of Phanerochaete chrysosporium INA-12 in relation to ligninase production. Applied Microbiol Biotechnol 27: 393 - 398

Cabuk A, Taspinar A, Kolankaya N (2006) Biodegradation of cyanide by a white rot fungus Trametes versicolor. Biotechnol Lett 28(16): 1313-1317

Calvo AM, Wilson RA, Bok JW, Keller NP (2002) Relationship between secondary metabolism and fungal development. Microbiol and Mol Biol Reviews 66(3): 447-459

Govender S, Pillay VL, Odhav B (2010) Nutrient manipulation as a basis for enzyme production in a gradostat bioreactor Enz Microbial Technol 46: 603-609

Govender S, Leukes WD, Odhav B, Pillay VL (2004) Towards an optimised spore immobilisation strategy using $P$. chrysosporium, reverse filtration and UF membranes. J Mem Sci 238: 83-92

Govender S, Jacobs EP, Leukes WD, Pillay VL (2003) A scalable membrane gradostat reactor for enzyme production. Biotechnol Lett 25: 127-13

Gow NR, Gadd GD (1995) The growing fungus. Chapman and Hall, London 
Guitierrez A, Martinez MJ, Almendros G, Gonzales-Vila FJ, Martinnez AT (1995) Hyphal sheath polysaccharides in fungal deterioration. Science Total Environ 167: 315-328

Leukes WD, Jacobs EP, Rose PD, Sanderson RD, Burton SG (1996) Secondary metabolite production. RSA patent 95/7366

Mikiashvili N, Elisashvili V, Wasser S, Nevo E (2005) Carbon and nitrogen sources influence the ligninolytic activity of Trametes versicolor. Biotechnol Lett 27: 955-959

Ntwampe NK, Sheldon MS, Volschenk V (2008) Limitations in a membrane gradostat bioreactor for enzyme production from biofilms of Phanerochaete chrysosporium. Wat Sci Technol 58(11): $2259-70$

Pusztahelyi T, Boswinkel G, van’t Riet K (1992) Parameters influencing hydrolysis kinetics in a hydrophilic membrane bioreactor. Enzyme Microb Technol 14: 214-220

Rittman BE, Trinet F, Amar D, Chang HT (1992) Measurement of the activity of a biofilm. Wat Sci Technol 26(3-4): 585-594

Venkatadri R, Irvine RL (1993) Cultivation of $P$. chrysosporium and production of LiP in novel biofilm reactor systems. Appl Environ Microbiol 56(9): 2684-2691

Table 1 Dimensions and operating conditions of the gradostat bioreactor (See Fig. 2)

\begin{tabular}{|c|c|}
\hline Parameter & Details \\
\hline Membrane surface area & $0.01357 \mathrm{~m}^{2}$ \\
\hline Extra-capillary reactor volume & $0.001145 \mathrm{~m}^{3}$ \\
\hline Growth medium supply regime & Constant flux \\
\hline Permeate flow-rate & 0.0100 to $0.0171 . \mathrm{d}^{-1}$ \\
\hline Oxygen supply rate & 1 vol. $(\operatorname{vol~ECS})^{-1} \cdot \mathrm{min}^{-1}$ \\
\hline Air flow regime & Transverse to capillaries \\
\hline Temperature control & Lagged shell $\left(37^{\circ} \mathrm{C}\right)$ \\
\hline
\end{tabular}




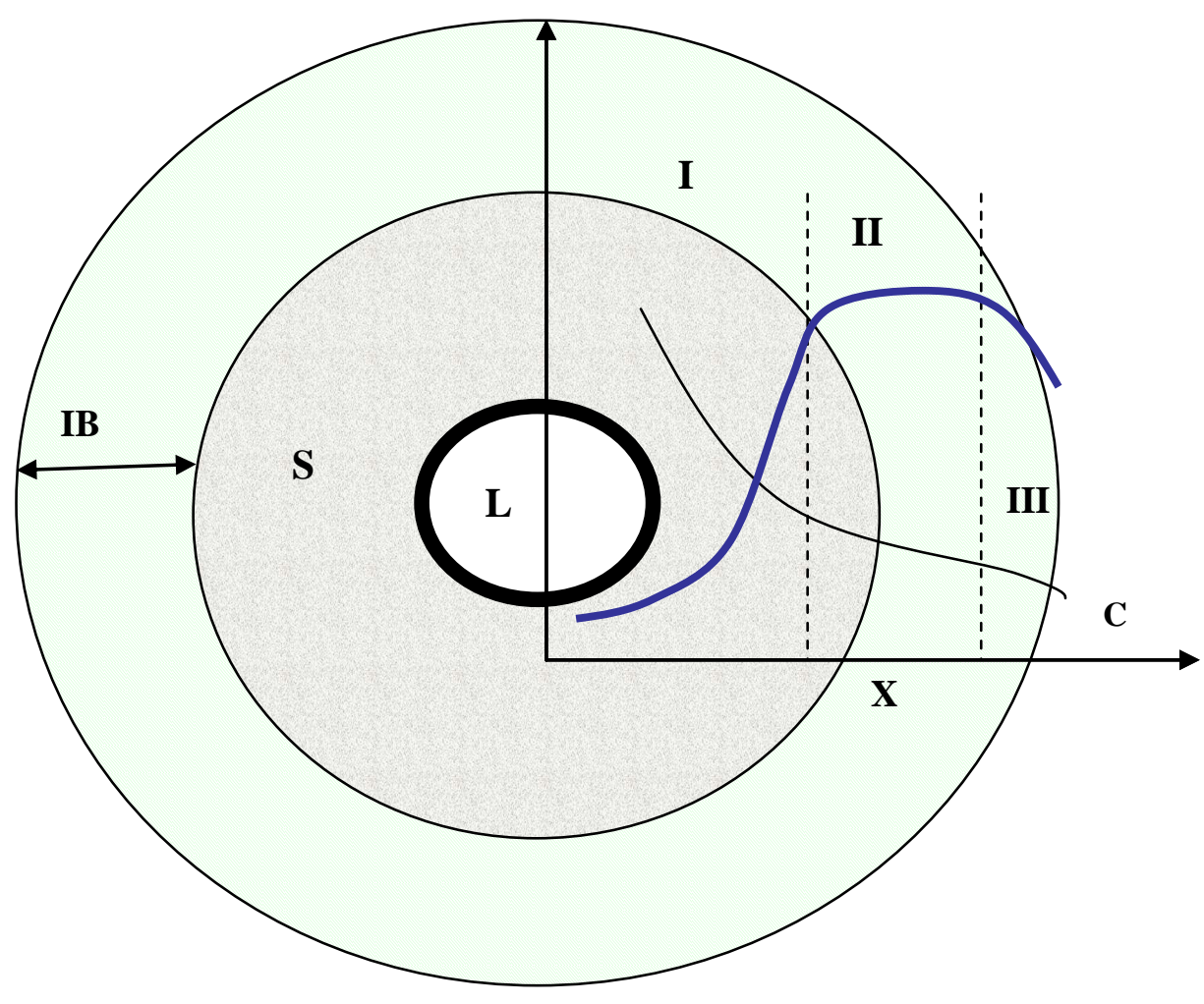



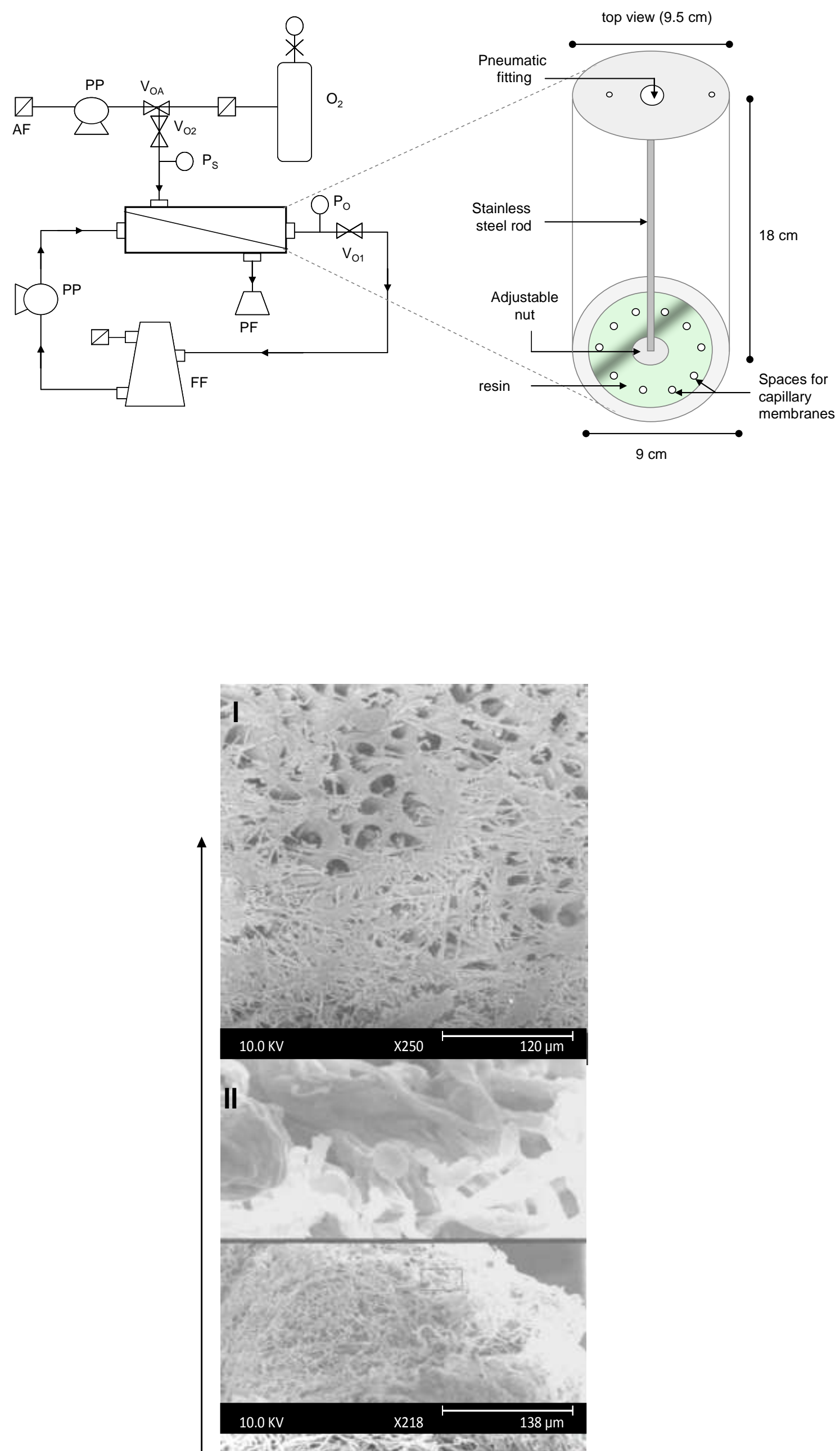

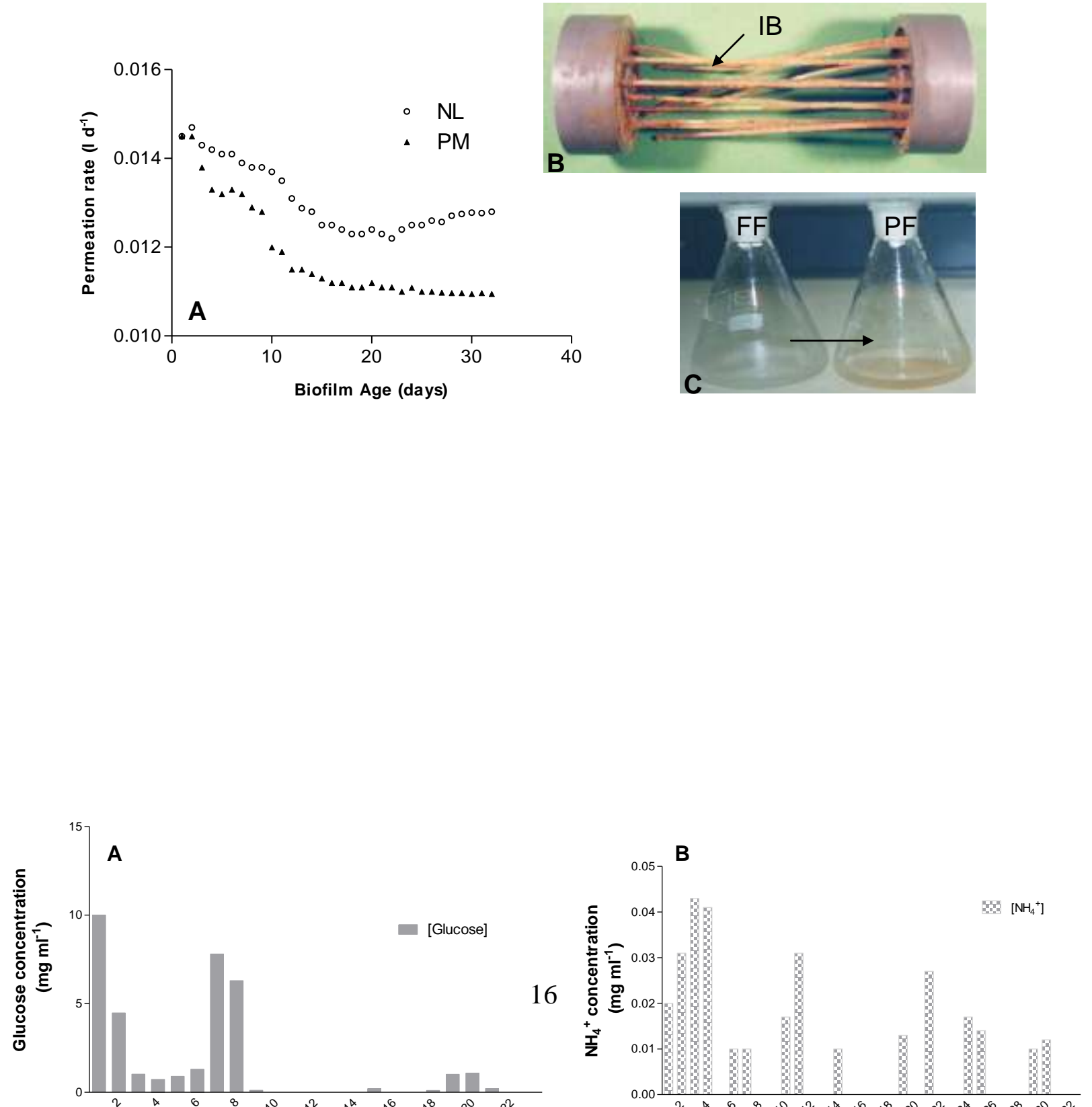

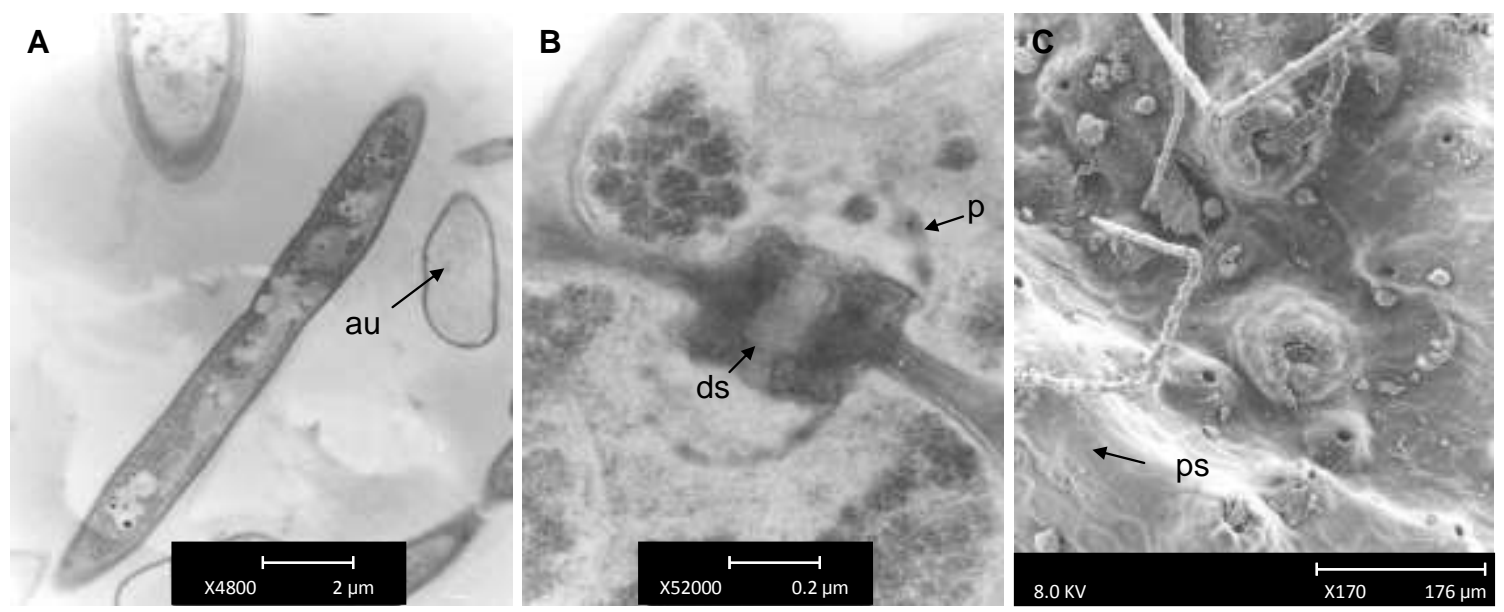
Fig. 1 Illustration of the membrane gradostat concept with superimposed batch culture growth curves. (I) primary growth phase, (II) stationary phase, (III) decline phase. IB is the immobilised biomass, $\mathrm{S}$ is the ultrafiltration membrane skin layer, $\mathrm{L}$ is the lumen of the membrane capillary from which the growth medium is supplied, $\mathrm{X}$ is the radial distance from the lumen in the direction of nutrient flow and $\mathrm{C}$ is the concentration of the growth-limiting substrate

Fig. 2 Process flow diagram of MGR operation: PP - Peristaltic pump; $\mathbf{O}_{2}-$ oxygen/air inlet. The complete process flow diagram for membrane gradostat operation in continuous mode; $\mathbf{A F}$ Air Filter; Po - Outlet Pressure Guage; Ps - Shell Pressure Guage; FF - Feed Flask; PF - Permeate Flask; $\mathbf{V}_{\mathbf{0 1}}$ - Valve (Tube Side); $\mathbf{V}_{\mathbf{O A}}$ - Valve (Shell side); Vo - Valve (Tube side); $\mathbf{O}_{\mathbf{2}}-100 \%$ Oxygen. Inset: Schematic illustration of the MGR module

Fig. 3 SEM composite profile showing the white rot fungi growth phases radially within the membrane immobilised biomass. (I) primary growth phase (bar $=120 \mu \mathrm{m})$, (II) stationary growth phase (bar $=138 \mu \mathrm{m})$, (III) decline phase $(\mathrm{bar}=150 \mu \mathrm{m})$. The arrow indicates the direction closest to lumen or bulk nutrient flow

Fig. 4 (A) MGR permeate profile where NL is the nutrient limiting feed and PM is the production medium; (B) visual assessment of immobilised ligninolytic biofilm (IB) on membrane 
surfaces after 33 days (total module length $=28 \mathrm{~cm}$ and width $=9.5 \mathrm{~cm}$ ) and $(\mathrm{C})$ ligninase induced colour change from colourless in the feed flask (FF) to brown in the permeate flask (PF)

Fig. 5 MGR profiles depicting (A) permeate glucose concentration; (B) permeate $\mathrm{NH}^{4+}$ concentration and (C) MnP productivity profile where $\mathrm{NL}=$ nutrient limited media with an average productivity of $22.48 \mathrm{U} \mathrm{l}^{-1} \mathrm{~d}^{-1}$ and the $\mathrm{PM}=$ production media or control yielded an average of $32.13 \mathrm{U} \mathrm{l}^{-1} \mathrm{~d}^{-1}$

Fig. 6 Analysis of surface 33 day old immobilised mycelium at the end of the MGR operation cycle. (A) TEM image showing autolysis (au) in a transverse section of the membrane (bar $=2 \mu \mathrm{m})$, (B) TEM image of dolipore septum (ds) and parenthesome (p) formation (bar $=0.2 \mu \mathrm{m}$ ) and (C) SEM image of polysaccharide sheath (ps) build up on the capillary surface towards the end of the operation cycle (day 33) in necrotic regions of the immobilised biomass. Bar $=176 \mu \mathrm{m}$ 